\title{
Correction
}

\section{Correction: Huang et al., Optogenetic Assessment of Horizontal Interactions in Primary Visual Cortex}

In the article "Optogenetic Assessment of Horizontal Interactions in Primary Visual Cortex" by Xiaoying Huang, Yishai M. Elyada, William H. Bosking, Theo Walker, and David Fitzpatrick, which appeared on pages 4976-4990 of the April 2, 2014 issue, the authors wish to acknowledge a relevant reference that was not cited in the original publication:

Chavane F, Sharon D, Jancke D, Marre O, Frégnac Y, Grinvald A (2011) Lateral spread of orientation selectivity in V1 is controlled by intracortical cooperativity. Front Syst Neurosci 5:4. CrossRef Medline

In Chavane et al. (2011), the authors present evidence that, under certain visual stimulus conditions, the lateral spread of subthreshold activity in visual cortex lacks orientation specificity. This observation is consistent with the results reported in Huang et al. (2014) that were derived from direct channel rhodopsin activation of layer 2/3 neurons. Chavane et al. (2011) also showed that other visual stimulation conditions resulted in an orientation-specific spread of activity, an effect that was not observed with the channel rhodopsin stimulation conditions employed in Huang et al. (2014).

DOI: 10.1523/JNEUROSCI.2207-14.2014 